\title{
Interaction of Droop Control Structures and its Inherent Effect on the Power Transfer
} Limits in Multi-terminal VSC-HVDC

Thams, Florian; Eriksson, Robert; Molinas, M.

\section{Published in:}

IEEE Transactions on Power Delivery

Link to article, DOI:

10.1109/TPWRD.2016.2600028

Publication date:

2016

Document Version

Peer reviewed version

Link back to DTU Orbit

\section{Citation (APA):}

Thams, F., Eriksson, R., \& Molinas, M. (2016). Interaction of Droop Control Structures and its Inherent Effect on the Power Transfer Limits in Multi-terminal VSC-HVDC. IEEE Transactions on Power Delivery, 32(1), 182 - 192. https://doi.org/10.1109/TPWRD.2016.2600028

\section{General rights}

Copyright and moral rights for the publications made accessible in the public portal are retained by the authors and/or other copyright owners and it is a condition of accessing publications that users recognise and abide by the legal requirements associated with these rights.

- Users may download and print one copy of any publication from the public portal for the purpose of private study or research.

- You may not further distribute the material or use it for any profit-making activity or commercial gain

- You may freely distribute the URL identifying the publication in the public portal 


\title{
Interaction of Droop Control Structures and its Inherent Effect on the Power Transfer Limits in Multi-terminal VSC-HVDC
}

\author{
F. Thams, Graduate Student Member, IEEE, R. Eriksson, Senior Member, IEEE, M. Molinas, Member, IEEE
}

\begin{abstract}
Future multi-terminal HVDC systems are expected to utilize de voltage droop controllers and several control structures have been proposed in literature. This paper proposes a methodology to analyse the impact of various types of droop control structures using small-signal stability analysis considering all possible combinations of droop gains. The different control structures are evaluated by the active power transfer capability as a function of the droop gains, considering various possible stability margins. This reveals the flexibility and robustness against active power flow variations, due to disturbances for all the implementations. A case study analyzing a three terminal HVDC VSC-based grid with eight different kinds of droop control schemes points out that three control structures outperform the remaining ones. Additionally, a multi-vendor case is considered where the most beneficial combinations of control structures has been combined in order to find the best performing combination.
\end{abstract}

Index Terms-Power system stability, Power transmission, stability, HVDC transmission, AC-DC power converters, Stability analysis, Control system analysis, State-space methods

\section{INTRODUCTION}

$\mathbf{T}$ HE rising number of offshore wind farm projects far away from the coast, as well as the need to connect those often remote RES to the major load centers, led to an increase of interest in HVDC technology in the last decade. The first commercial application of HVDC transmission was built in 1954 between Gotland and the Swedish mainland based on mercury valves [1]. Since then, most HVDC links based on line commutated converters (LCC) were built in point-to-point connections besides few exceptions (e.g. in Sardinia-CorsicaItaly and Quebec New England [2]).

The appearance and development of HVDC transmission based on voltage source converter (VSC) and its advantages compared to HVDC based on LCC raised the interest in connecting more than two terminals to a multi-terminal grid. These advantages include the capability of controlling active and reactive power independently, the capability to supply

This project is co-funded by the European Unions Seventh Framework Programme for Research, Technological Development and Demonstration under the grant agreement no. 612748 .

F. Thams is with the Center of Electric Power and Energy (CEE), Technical University of Denmark (DTU), DK-2800 Kgs. Lyngby, Denmark (e-mail: fltha@elektro.dtu.dk).

Robert Eriksson was with the Center for Electric Power and Energy (CEE), Technical University of Denmark (DTU), DK-2800 Kgs. Lyngby, Denmark. He is now with the Swedish National Grid (e-mail: errobban@gmail.com).

M. Molinas is with the Department of Engineering Cybernetics, Norwegian University of Science and Technology (NTNU), 7491 Trondheim, Norway (email: marta.molinas@ntnu.no). weak grids and especially the ease of achieving power flow reversal.

In Europe, ten countries of the North sea region formed the North Seas Countries Offshore Grid Initiative (NSCOGI) in order to explore the best way to establish an offshore HVDC grid [3]. In China, however, two multi-terminal HVDC (MTHVDC) grids have already been built [4], [5].

Due to the little experience with multi-terminal grids, the control of such a HVDC grid is an emerging research topic. The operational reliability is a crucial aspect due to the significant economic impact of any malfunction. In case of a MT-HVDC system it is preferable to have a distributed control architecture, where multiple units are actively participating in the control of the grid based on local measurements. This leads to an inherently higher robustness against outages. Further, a distributed control architecture is more effective in case of power fluctuations that exceed the available control range of a single terminal [6], [7]. This is reflected by the fact that the vendors participating in the European HVDC Study Group prefer droop control or droop control together with deadband as control structure for distributed voltage control [8]. Additionally, the applicability of droop control is proven by its use in the Nanao MT-HVDC grid [4].

In technical literature several alternative droop control schemes have been proposed [6], [9]-[18], which have been categorized in a simple framework in [19].

The general operation principle for all the dc voltage droop implementations is identical, i.e. each implementation contains two control loops, in order to assume a linear relationship between current respectively active power and dc voltage. However, it was shown that the choice of control objective for the first respectively the second loop, as well as the tuning, has a significant impact on the dynamic performances and the stability properties. This is especially important to consider in case of a MT-HVDC grid built by different vendors.

Although small-signal stability analysis has been carried out in MT-HVDC grids, a comparison of different dc voltage droop control structures is still missing. To the best knowledge of the authors, there does not exist any analysis to determine the most beneficial and flexible control structure in the context of a MT-HVDC grid yet. Further, there do not exist any studies on using different kinds of droop control structures within one grid and their impact on each other.

The contribution of this work encloses a methodology for a stability analysis of different droop control implementations, regarding the active power transfer capability as a function 
of the droop gains. This methodology is applied to analyse a MT-HVDC grid, which extends the work in [19], to emphasize the impact of different control structures. In the study case the flexibility against active power flow variations and robustness against disturbances will be compared and analyzed for all the various implementations.

Additionally, the stability limits of the most promising configurations will be analyzed and the limitations discussed in more detail. This will also provide further insight on how different droop controlled converters influence each other. Moreover, in contrast to previous publications, this work will investigate the consequences resulting from using different implementations simultaneously at different converter stations.

This paper is structured in four main parts. After the introduction a general model will be introduced and then the used methodology for analyzing the power transfer capability will be explained. Finally, a case study of a three terminal grid will be introduced and the findings will be discussed.

\section{MATHEMATHICAL MODEL}

A general mathematical model of a VSC-HVDC terminal with simplified ac grid will be presented in the following sections. This model is based on the single VSC configuration introduced in [20]. In order to develop a multi-terminal grid, an arbitrary number of those terminals and lines can be connected.

\section{A. Model Conventions}

Upper case letters represent physical values of the electrical circuit, whereas lower case letters define per unit quantities. The apparent power rating of the converter and the peak value of the rated phase voltage serve as base values for the used per unit system. The modelling of the electrical system and the control of the ac-side will be presented in a synchronous reference frame (SRF), using the amplitude-invariant Park Transformation. The d-axis voltage vector is aligned with the voltage vector, $v_{o}$, at the corresponding filter capacitor, $c_{f}$, and the q-axis is leading the $\mathrm{d}$-axis by $90^{\circ}$ [1]. SRF equations will be noted in complex space vector notation according to

$$
\mathbf{x}=x_{d}+j \cdot x_{q}
$$

\section{B. Electrical System}

As shown in Fig. 1, a simplified but appropriate model for this analysis is used. The focus on the outer control loop, as well as the emphasis on small signal analysis, justifies this simplification for a multi-terminal grid in order to minimize the large computational burden.

1) Electrical System on the AC Side: As shown in Fig. 1, a simplified model of the ac grid is assumed, using an LC filter as the grid interface of the VSC and a Thévenin equivalent representation of the grid. The state-space equations can be

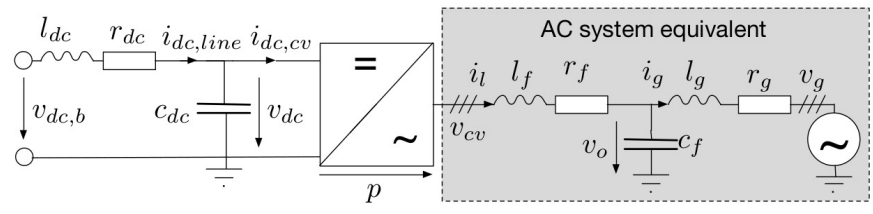

Fig. 1. Model of a VSC-HVDC terminal connected to a single dc line

obtained as given below, where the per unit grid frequency is denoted as $\omega_{g}$ and the base angular frequency as $\omega_{b}$ [21], [22].

$$
\begin{aligned}
\frac{d \mathbf{i}_{l}}{d t} & =\frac{\omega_{b}}{l_{f}} \mathbf{v}_{c v}-\frac{\omega_{b}}{l_{f}} \mathbf{v}_{o}-\left(\frac{r_{f} \omega_{b}}{l_{f}}+j \cdot \omega_{g} \omega_{b}\right) \mathbf{i}_{l} \\
\frac{d \mathbf{v}_{o}}{d t} & =\frac{\omega_{b}}{c_{f}} \mathbf{i}_{l}-\frac{\omega_{b}}{c_{f}} \mathbf{i}_{g}-j \cdot \omega_{g} \omega_{b} \mathbf{v}_{o} \\
\frac{d \mathbf{i}_{g}}{d t} & =\frac{\omega_{b}}{l_{g}} \mathbf{v}_{o}-\frac{\omega_{b}}{l_{g}} \mathbf{v}_{g}-\left(\frac{r_{g} \omega_{b}}{l_{g}}+j \cdot \omega_{g} \omega_{b}\right) \mathbf{i}_{g}
\end{aligned}
$$

The power balance between ac and dc side is given below. It is based on the assumption of an ideal lossless average model for the converter.

$$
v_{c v, d} \cdot i_{l, d}+v_{c v, q} \cdot i_{l, q}=v_{d c} \cdot i_{d c, c v}
$$

2) Electrical System on the DC Side: On the dc side, the lines are represented as single pi-equivalents, where the capacitances are incorporated in the dc capacitance of the corresponding converter, as given in (6).

$$
c_{d c}=\frac{c_{d c, l i n e}}{2}+c_{d c, v s c}
$$

It is worth to note that this is a simplified model, which can approximate only the lowest frequency resonant peak of the cable [12]. But, on the other hand, D'Arco argues in [20], this approach also resembles the worst case scenario with respect to LC oscillations. This is due to the fact that the oscillatory effects are condensed in a single frequency, instead of being spread on several frequencies as in a real cable. This modeling approach can also be justified by the results of [23], indicating that for an appropriate sizing of the capacitor the impedance

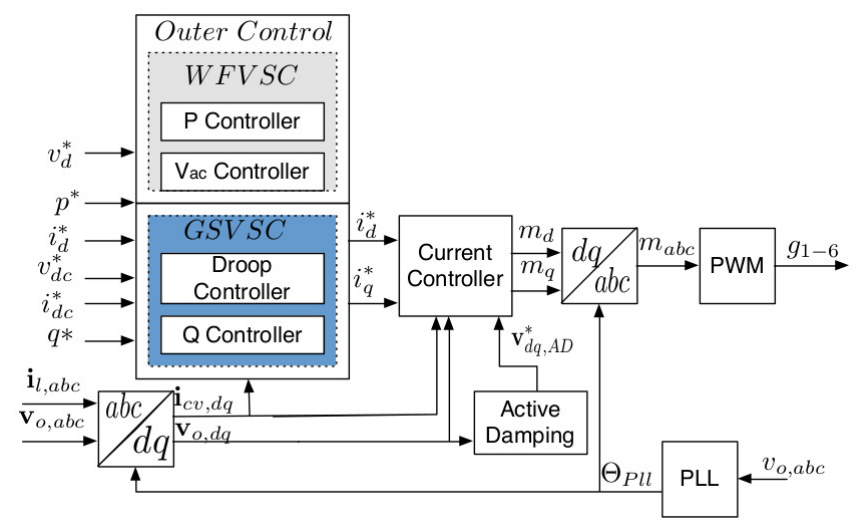

Fig. 2. Control system GSVSC and WFVSC differ by outer controllers, GSVSCs differ by chosen droop control structure (CS) 
seen by the VSC is almost identical. The equations for the dynamics at the dc capacitors are given by:

$$
\frac{d v_{d c}}{d t}=\frac{\omega_{b}}{c_{d c}} i_{d c, l i n e}-\frac{\omega_{b}}{c_{d c}} i_{d c, c v}
$$

Whereas the dc line dynamics according to the defined current flow are given by:

$$
\frac{d i_{d c, l i n e}}{d t}=\frac{\omega_{b}}{l_{d c}} v_{d c, b}-\frac{\omega_{b}}{l_{d c}} v_{d c}-\frac{\omega_{b} r_{d c}}{l_{d c}} i_{d c, l i n e}
$$

\section{Control System}

The control system consists of an active damping of LC filter oscillations for the ac side, a current controller, a PLL and an outer controller. The outer control depends on the connected ac grid, which is explained in more detail in the outer loop controller subsection. An overview of the control system is given in Fig 2. The corresponding equations are given in the following subsections.

1) PLL: The VSC is assumed to be synchronized with the corresponding ac grid through a PLL, modelled as shown in Fig. 3 [22], [24]. An inverse tangent function is used on the low-pass filtered estimated phase voltages $\mathbf{v}_{P L L}$ to approximate the actual phase angle error $\Delta \Theta_{v, P L L}$. Followed by a PI controller in order to derive the frequency of the tracked voltages. The corresponding equations are given as:

$$
\begin{aligned}
\frac{d \mathbf{v}_{P L L}}{d t} & =-\omega_{L P, P L L} \mathbf{v}_{P L L}+\omega_{L P, P L L} \mathbf{v}_{o} \\
\frac{d \epsilon_{P L L}}{d t} & =\tan ^{-1}\left(\frac{v_{P L L, q}}{v_{P L L, d}}\right) \\
\frac{d \Delta \Theta_{v, P L L}}{d t} & =\omega_{b} \Delta \omega_{P L L}
\end{aligned}
$$

with $\epsilon_{P L L}$ representing the integrator state of the PI controller and $\Delta \Theta_{P L L}$ the phase angle deviation between the grid voltage, $\mathbf{v}_{g}$, and the orientation of the PLL. $\Delta \omega_{P L L}$ describes the grid frequency deviation. The deviation variables are necessary for the modeling of the PLL in the SRF. While the actual voltage vector phase angle, $\Theta_{P L L}$, obtained, as shown in Fig. 3 , is needed for the transformation between stationary and rotating reference frame.

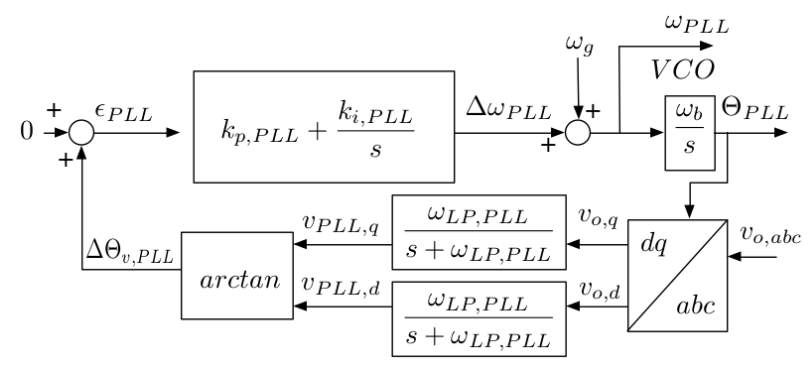

Fig. 3. Phase Locked Loop

2) Active Damping of LC Filter Oscillations: An active damping of LC filter oscillations is implemented, based on injecting a component, $\mathbf{v}_{A D}^{*}$, to the converter output voltage, which is in counter-phase with the detected oscillations [25], [26].

$$
\begin{aligned}
\mathbf{v}_{A D}^{*} & =k_{A D}\left(\mathbf{v}_{o}-\phi\right) \\
\frac{d \phi}{d t} & =\omega_{A D} \mathbf{v}_{o}-\omega_{A D} \phi
\end{aligned}
$$

While $\omega_{A D}$ represents the cut-off frequency and $\phi$ the integrator states of the low-pass filter, $k_{A D}$ is used as tuning parameter depending on the dynamic response of the system.

3) Inner Current Control Loop: The inner current control is based on vector control in the synchronous reference frame, tuned by modulus optimum criterion [27]. Considering two conventional PI controllers with decoupling terms and voltage feed-forward, the converter output voltage reference, $\mathbf{v}_{c v}^{*}$, can be defined as:

$$
\mathbf{v}_{c v}^{*}=k_{p c}\left(\mathbf{i}_{l}^{*}-\mathbf{i}_{l}\right)+k_{i c} \gamma+j l_{f} \omega_{P L L} \mathbf{i}_{l}+\mathbf{v}_{o}-\mathbf{v}_{A D}^{*}
$$

with $\gamma, k_{p c}$ and $k_{i c}$ representing the integrator state, the proportional and integral gain of the PI controller.

4) Outer Loop Controller: The outer loop control structure is the main difference between the terminals. Here, a distinction is made between VSC terminals, which are supposed to take part in the dc voltage control, and those which are not. The former are most likely connected to rather strong grids, hence those terminals are called grid side VSC (GSVSC) in the following. The latter is most likely connected to rather weak grids, where the focus lies on maximizing the power output as it is for wind farms, hence those are called wind farm VSC (WFVSC) in the following. This paper focuses on the outer loop control structure of the GSVSCs, in particular how different droop control structures influence the power transfer limits of the whole system.

a) Wind Farm Converter (WFVSC): For a VSC terminal representing a wind farm, a conventional active power controller is providing the d-axis current reference. The qaxis reference is provided by an ac voltage controller. The equations are given as:

$$
\begin{aligned}
& i_{l, d, w f}^{*}=k_{p c d, w f}\left(p_{w f}^{*}-p_{w f, a c}\right)+k_{i c d, w f} \chi_{d, w f} \\
& i_{l, q, w f}^{*}=k_{p c q, w f}\left(v_{o, d, w f}^{*}-v_{o, d, w f}\right)+k_{i c q, w f} \chi_{q, w f}
\end{aligned}
$$

with $\chi_{d / q}, k_{p c d / q}$ and $k_{i c d / q}$ representing the integrator state, the proportional and integral gain of the PI controller.

b) Grid Side Converter (GSVSC): The q-axis current reference for a VSC terminal connected to a strong grid is provided by a reactive power controller.

$$
i_{l, q, g}^{*}=k_{p c q, g}\left(q_{g}^{*}-q_{g}\right)+k_{i c q, g} \chi_{q, g}
$$

The d-axis current reference is provided by one of the various dc voltage droop controllers, identified and categorized in [19] and shown in Fig. 4. The block diagrams of the corresponding droop controller indicate that these droop controllers differ regarding:

- power or current based droop implementations

- the choice of the second variable (besides dc voltage): current / power measured on ac or dc side

- the choice on which variable the droop gain $k_{\text {droop }}$ is applied, i.e. which variable is controlled in the first and which in the second loop 

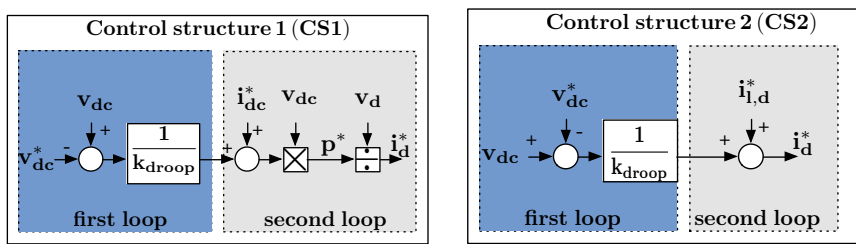

(a) Control Structure 1 - (18)

(b) Control Structure 2 - (19) Ref: [6], [12], [14], [15], [17], [18], [28] Ref: [16], [29], [30]

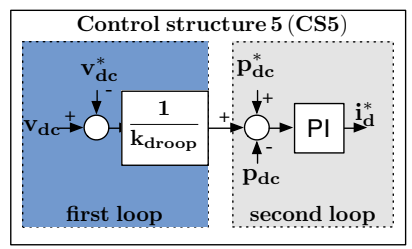

(e) Control Structure 5 - (22) Ref: [11], [33]-[35]

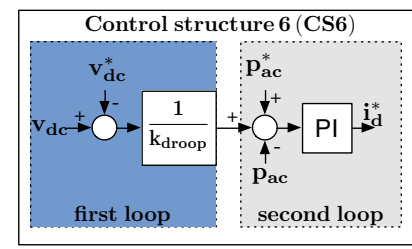

(f) Control Structure 6 - (23) Ref: [35]

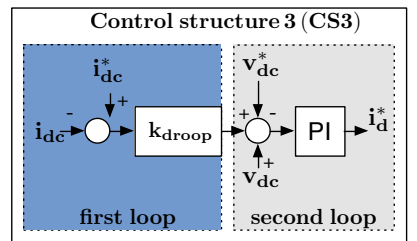

(c) Control Structure 3 - (20) Ref: [10], [31], [32]

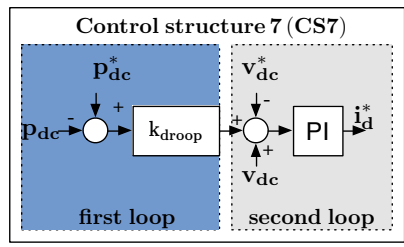

(g) Control Structure 7 - (24) Ref: [36], [37]

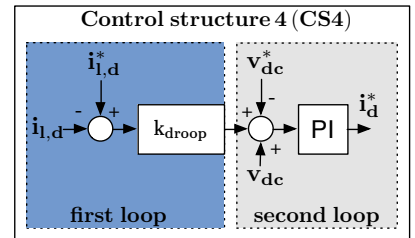

(d) Control Structure 4 - (21) Ref: [19]

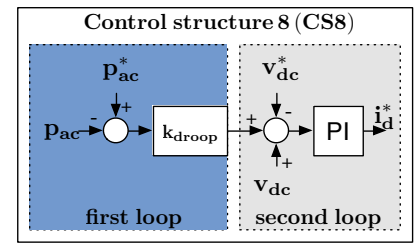

(h) Control Structure 8 - (25) Ref: [37]

Fig. 4. Analysed DC Voltage Droop Control Structures

The corresponding equations of those controllers are given in (18)-(25) in the order of control structure (CS) 1 to 8.

$$
\begin{aligned}
\mathrm{CS} 1: i_{l, d, g}^{*}= & \frac{\left(\frac{v_{d c}-v_{d c}^{*}}{k_{d r o o p}}+i_{d c}^{*}\right) \cdot v_{d c}}{v_{o, d}} \\
\mathrm{CS} 2: i_{l, d, g}^{*}= & \frac{v_{d c}-v_{d c}^{*}}{k_{d r o o p}}+i_{a c}^{*} \\
\mathrm{CS} 3: i_{l, d, g}^{*}= & k_{p c d, g}\left(\left(i_{d c}^{*}-i_{d c}\right) \cdot k_{d r o o p}+v_{d c}-v_{d c}^{*}\right) \\
& +k_{i c d, g} \chi_{d, g} \\
\mathrm{CS} 4: i_{l, d, g}^{*}= & k_{p c d, g}\left(\left(i_{a c}^{*}-i_{a c}\right) \cdot k_{d r o o p}+v_{d c}-v_{d c}^{*}\right) \\
& +k_{i c d, g} \chi_{d, g} \\
\mathrm{CS} 5: i_{l, d, g}^{*}= & k_{p c d, g}\left(\frac{v_{d c}-v_{d c}^{*}}{k_{d r o o p}}+p_{d c}^{*}-p_{d c}\right) \\
& +k_{i c d, g} \chi_{d, g} \\
\mathrm{CS} 6: i_{l, d, g}^{*}= & k_{p c d, g}\left(\frac{v_{d c}-v_{d c}^{*}}{k_{d r o o p}}+p_{a c}^{*}-p_{a c}\right) \\
& +k_{i c d, g} \chi_{d, g} \\
\mathrm{CS} 7: i_{l, d, g}^{*}= & k_{p c d, g}\left(\left(p_{d c}^{*}-p_{d c}\right) \cdot k_{d r o o p}+v_{d c}-v_{d c}^{*}\right) \\
& +k_{i c d, g} \chi_{d, g} \\
\mathrm{CS} 8: i_{l, d, g}^{*}= & k_{p c d, g}\left(\left(p_{a c}^{*}-p_{a c}\right) \cdot k_{d r o o p}+v_{d c}-v_{d c}^{*}\right) \\
& +k_{i c d, g} \chi_{d, g}
\end{aligned}
$$

\section{METHODOLOGY}

The differences between the various dc voltage droop controllers are analyzed in terms of active power transfer capability as a function of the droop gains of the connected GSVSCs using droop control. That means by using eigenvalue analysis, the eigenvalue movement is analyzed for a variation of the disturbances (= power injection at uncontrolled dc nodes / WFVSCs) and a variation of the droop gains. The sensitivity of certain eigenvalues for a variation of these parameters is shown in Fig. 5. For each combination of these parameters, the nonlinear system is linearized and the steady state is evaluated with respect to the chosen requirements for an acceptable operation point. These requirements can be chosen by the user applying the method and could include e.g. specific stability margins and / or current / voltage limitations. This analysis will basically result in a set of acceptable operation points, which are plotted with respect to the power transferred at a specific terminal. The surfaces of this area of acceptable operation points in this plot illustrate the upper and lower boundary (both directions of power flow) of acceptable operation for a specific combination of droop gains at each terminal. This set of acceptable operation points varies with respect to the chosen requirements. In contrast to other publications using small signal analysis, this methodology helps to determine the range of acceptable operation for a specific terminal within a multiterminal grid for various control structures with all possible droop gain combinations and any arbitrary requirement. This operating range is expressed as a range of possible power flows at that terminal for a specific droop gain combination. Therefore, it is referred to as active power transfer capability (APTC) in the following.

Finally, the steady states at the boundary of the APTC are analyzed by a participation factor analysis, in order to identify the states associated with the modes causing the violation of a specific stability margin. This provides insight in determining the origin of the boundary and identifies which part of the system is provoking the limit.

Here, this analysis is used to illustrate the focus of this paper: revealing the impact of the choice of the droop control structure on the APTC for different exemplary requirements for an acceptable operation point. Since the models differ only in terms of the droop control structures, this analysis allows to determine which effect each control structure has on the APTC of each terminal and the whole system. Further, it reveals which control structures are more beneficial than others in terms of the APTC. Additionally, in the planning phase of a multi-vendor multi-terminal HVDC grid, probably 


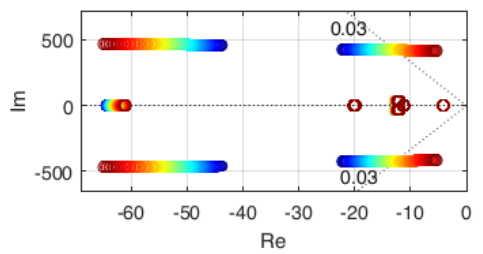

(a)

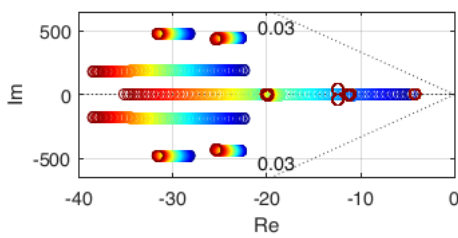

(b)

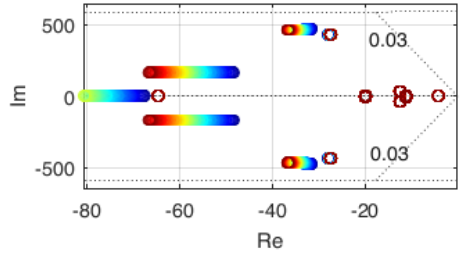

(c)

Fig. 5. Visualization of the sensitivity of certain eigenvalues and the stability margin of a minimum damping ratio of $3 \%$. The pole movement is shown for a variation of a) $p_{w f}$ from 0 p.u. (blue) to 1 p.u. (red), b) $k_{\text {droop }}$ from 0 (blue) to 0.1 (red) and c) $k_{d r o o p_{g} s}$ from 0 p.u. (blue) to 0.1 p.u. (red) for otherwise fixed values of $p_{w f}=0 \mathrm{pu}, k_{\text {droop }}=0.1 \mathrm{p}$.u. and $k_{d r o o p, g s 2}=0.1 \mathrm{p} . \mathrm{u}$.

using different kind of droop control structures, the analysis facilitates to determine more or less beneficial combinations of control structures. Moreover, by analyzing these boundaries along the variation of the droop gains, it provides insight on how the choice of the droop gain values affects the APTC during operation. Additionally, it indicates whether a certain ratio of the droop gain values may be beneficial for maximizing the APTC.

\section{A. Flowchart of the Methodology}

The methodology is shown in detail in Fig. 6, as an example for a three terminal model, as it is used in the case study. The methodology can, however, also be applied to other topologies, the visualization of the APTC just becomes more challenging in case of a higher number of terminals.

First, a range of values for the droop gains, as well for the disturbance resembled by the power injection of the uncontrolled dc node, needs to be defined. Here, the values of the disturbances will define the power flow, while the droop gains

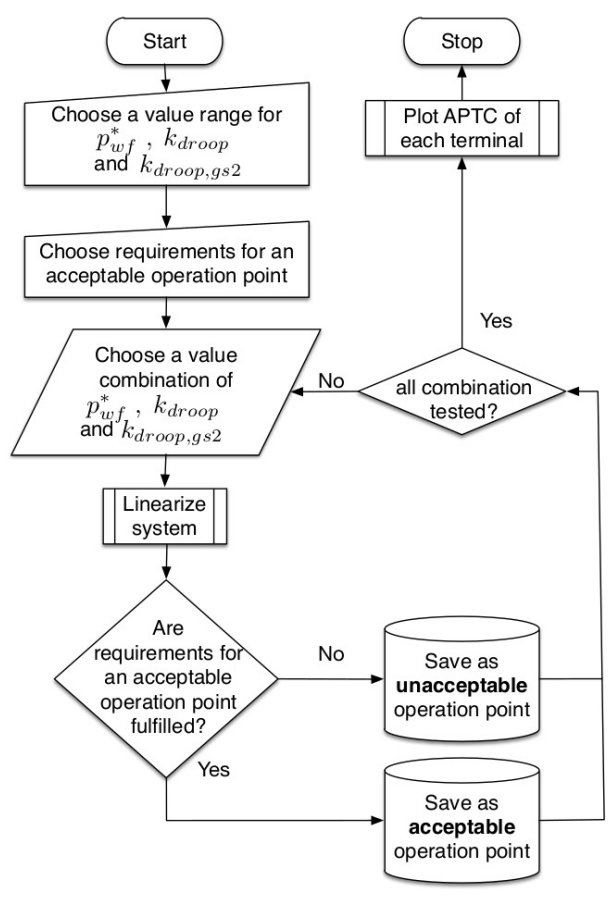

Fig. 6. Flowchart of Methodology will define the power sharing between the terminals. In the case study, a value range of 0.0001 p.u. $\leq k_{\text {droop }} \leq 0.1$ p.u. and -2 p.u. $\leq p_{w f}^{*} \leq 2$ p.u. was chosen, however, the ranges can be chosen by the user applying the method according to the analyzed system. Additionally, any arbitrary requirement for an acceptable operation point can be chosen, which can include (several) stability margins and/or current/voltage requirements. Then, the first combination of values is chosen and the nonlinear system obtained from the aforementioned equations is linearized for the given inputs. It is analyzed whether the steady state meets current and voltage limits and whether the eigenvalues satisfy the requirements of various possible stability margins. Depending on the results, the operation points are saved correspondingly and the next combination of values is analyzed.

\section{B. Requirements for an acceptable Operation Point}

As aforementioned any arbitrary requirement for an acceptable operation point can be chosen by the user applying the method. Since there are no grid codes or standardized requirements for acceptable operation points in MT-HVDC grids defined yet, in the case study the APTC is analyzed for three possible requirements in order to investigate whether a certain requirement (current/voltage limit or stability margin) limits specific control structures more than others.

1) Voltage and Current Limits: First, the APTC are analyzed only with respect to fulfill the current and voltage limits. Here, these limits are chosen according to the Cigré B4 DC Grid test system, i.e. the dc voltage operational frame is assumed to be between 0.95 p.u. and 1.05 p.u., while the maximum current in the dc cable is set to $2265 \mathrm{~A}$ [38].

2) Damping Ratio $\geq 3 \%$ : A minimum damping ratio of $3 \%$ is demanded for all eigenvalues [39].

3) Maximum DC Voltage deviation of 5\%: The performance of the control structures can be analysed by means of the singular value representation of the system transfer function matrices, $E_{w}(j \omega)$, according to [40]. The singular value representation can be obtained as:

$$
\sigma_{i}\left(E_{w}(j \omega)\right)=\sqrt{\lambda_{i}\left(E_{w}^{T}(j \omega) E_{w}(j \omega)\right)}
$$

where $\lambda_{i}$ is the $i$-eigenvalue of the matrix. The maximum singular value, $\bar{\sigma}(G(j \omega))$, indicates the maximum amplification of the corresponding inputs by the system seen from a specific output. The analysed inputs and outputs are the disturbance 
(wind power input) and the dc voltage errors at the GSVSCs. In [40] the authors derive the maximum gain the singular value representation should not exceed, in case a maximum voltage error of $10 \%$ of the nominal value at each terminal is assumed. Here, it is adapted to the per unit system and a maximum deviation of $5 \%$ is chosen as stability margin:

$$
\begin{aligned}
\bar{\sigma}\left(E_{w}(0)\right) \leq & \frac{\|e(0)\|_{2}}{\|w(0)\|_{2}}=20 \log _{10}\left(\frac{\sqrt{e_{\text {gsvsc } 1}+e_{\text {gsvsc } 2}}}{p_{w f v s c}}\right) \\
& =20 \log _{10}\left(\frac{\sqrt{(1 \cdot 0.05)^{2} \cdot 2}}{1}\right)=-23.01 \mathrm{~dB}
\end{aligned}
$$

\section{CASE STUDY}

A symmetric three terminal grid is derived from the aforementioned model, as shown in Fig. 8 (the ac sides are equal for all terminals as indicated by the ac system equivalent of the general model).

The GSVSCs use each one of the eight different droop control structures. First, both GSVSCs use the same CSs in order to detect the ones with highest APTC and highest damping ratios. Then, the most promising ones are combined with each other in order to determine the most beneficial combination of droop control structures. Each of these models consists of 5254 states depending on the dc voltage droop implementations used. All models have been derived using Maxima [41].

The analysis depends obviously on the given parameters and should therefore be selected as they appear in the system. In this case study, the dc voltage reference values for both GSVSCs are set to 1 p.u., while the current and active power reference values of the GSVSCs are set to 0.1 p.u.. The numerical values for the gains of the droop controller have been selected with respect to the aforementioned reference values to ensure comparable performances. In particular, if a PI controller is present, its tuning has been set to achieve a $5 \%$ overshoot for a $5 \%$ step in the dc voltage reference with a fast rise time of approx. $8 \mathrm{~ms}$ and a settling time of a few tens of milliseconds. Thus, it is chosen to be very fast compared to suggestions in the literature of up to few $100 \mathrm{~ms}$ [8] in order to approach the limits of the VSC. Additionally, a second tuning with a rise time in the range of tens of milliseconds and a settling time of $100 \mathrm{~ms}$ is used as reference case.

In order to ensure comparability but also not to be limited by the VSC representing the wind farm, the active damping of both GSVSCs are tuned equally, whereas a higher damping factor is chosen for the WFVSC.

All parameter and base values are given in appendix. The dc parameters are scaled into per unit by using the same base frequency as for the ac side, as shown in appendix. This results in apparently high values for per unit inductance and capacitance, however, these parameters are corresponding to a dc cable of about $67 \mathrm{~km}$ [20].

All used models are verified by time domain simulations with equivalent non-linear models built in Matlab SimPowerSystems, two validation plots are shown in Fig. 7.

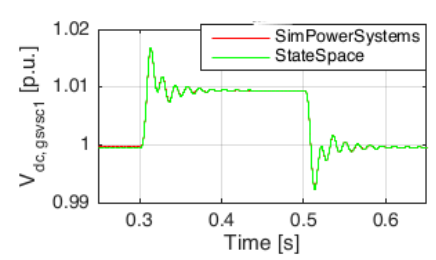

(a)

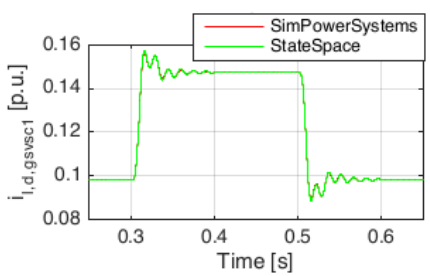

(b)
Fig. 7. Validation of the small signal model by a time domain simulation and comparison with a non-linear model built in Matlab SimPowerSystems. (Response of a) $v_{d c, g s 1}$ and b) $i_{l, d}$ to a $10 \%$ step in $p_{w f}^{*}$ ).

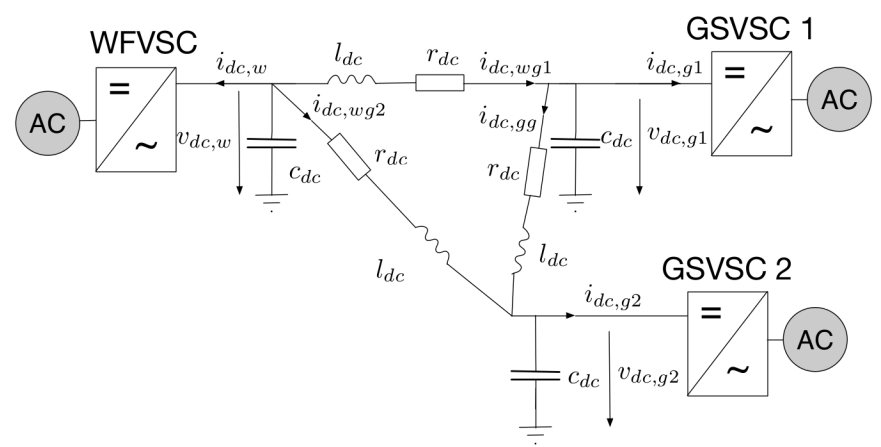

Fig. 8. Model of the dc grid

\section{A. Analysis of the Case where both GSVSCs use the same CS}

In this scenario the same control structure is used at GSVSC1 and GSVSC2. This is done in order to determine the operation ranges for each $\mathrm{CS}$ for the various requirements. In the following the APTCs are given for the case where the only requirements considered are the system stability $(\operatorname{Re}\{\lambda\} \leq 0)$ and the voltage and current limits given in the subsection III-B1. The impact of the remaining requirements are discussed in the corresponding subsections and highlighted in the respective tables. The APTC of the case in which both GSVSCs use CS 8 is shown in Fig. 9. Fig. 9a shows the maximum power transfer in both directions of one terminal for all combinations of $k_{d r o o p}$ and $k_{d r o o p, g s 2}$. That means with the given current definition shown in Fig. 1, the upper surface resembles the inverter limit of that GSVSC while the lower surface resembles the rectifier limit of that GSVSC. The area between both surfaces is the area of stable and acceptable operation points. Thus, the APTC of a single

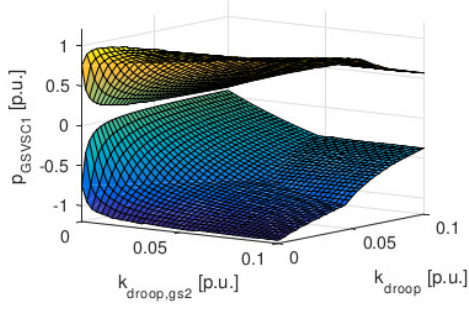

(a)

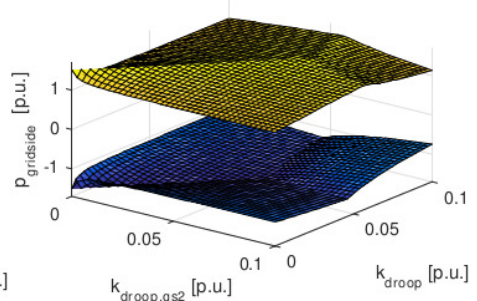

(b)
Fig. 9. APTC of a) GSVSC1 and b) the sum of both GSVSCs ( $p_{\text {gridside }}$ ) 
TABLE I

COMPARISON OF MAXIMUM APTC OF A SINGLE GSVSC FOR VARIOUS CONTROL STRUCTURES REQUIREMENTS: $:$ FULFILLED, FULFILLED BUT CLOSE TO BOUNDARY, $₫$ NOT FULFILLED

\begin{tabular}{|c|c|c|c|c|c|c|c|c|c|c|}
\hline \multirow{4}{*}{$\begin{array}{l}\text { Control } \\
\text { Structure }\end{array}$} & \multicolumn{5}{|c|}{ Fast Response Time } & \multicolumn{5}{|c|}{ Slow Response Time } \\
\hline & \multirow{3}{*}{$\begin{array}{c}\text { Max Range } \\
p_{g s v s c 1}\end{array}$} & \multirow{2}{*}{\multicolumn{2}{|c|}{$\begin{array}{c}\text { Damping Ratio } \\
\text { of lowest damped EV }\end{array}$}} & \multicolumn{2}{|c|}{$\bar{\sigma}\left(E_{w}(0)\right)$} & \multirow{3}{*}{$\begin{array}{c}\text { Max Range } \\
p_{g s v s c 1}\end{array}$} & \multirow{2}{*}{\multicolumn{2}{|c|}{$\begin{array}{c}\text { Damping Ratio } \\
\text { of lowest damped EV }\end{array}$}} & \multicolumn{2}{|c|}{$\bar{\sigma}\left(E_{w}(0)\right)$} \\
\hline & & & & \multirow{2}{*}{$\begin{array}{l}\text { lower } \\
\text { limit }\end{array}$} & \multirow{2}{*}{$\begin{array}{l}\text { upper } \\
\text { limit }\end{array}$} & & & & lower & upper \\
\hline & & 1. limit & u. limit & & & & 1. limit & u. limit & limit & limit \\
\hline CS 1 & 1.14 p.u. & $0.14 \%$ & $13.88 \%$ & $-46.1 \mathrm{~dB}$ & $-46.3 \mathrm{~dB}$ & & & & & \\
\hline CS 2 & 1.17 p.u. & $5.27 \%$ & $0.02 \%$ & $-54.4 \mathrm{~dB}$ & $-54.5 \mathrm{~dB}$ & & & & & \\
\hline CS 3 & 2.23 p.u. & $6.86 \%$ & $7.62 \%$ & $-51 \mathrm{~dB}$ & $-51.6 \mathrm{~dB}$ & 2.23 p.u. & $0.35 \%$ & $6.19 \%$ & $-50.8 \mathrm{~dB}$ & $-51.4 \mathrm{~dB}$ \\
\hline CS 4 & 2.23 p.u. & $7.26 \%$ & $7.72 \%$ & $-51.4 \mathrm{~dB}$ & $-52 \mathrm{~dB}$ & 2.16 p.u. & $0.41 \%$ & $6.14 \%$ & $-51.1 \mathrm{~dB}$ & $-51.8 \mathrm{~dB}$ \\
\hline CS 5 & 1.34 p.u. & $0.05 \%$ & $13.1 \%$ & $-27.2 \mathrm{~dB}$ & $-27.4 \mathrm{~dB}$ & 1.87 p.u. & $0.03 \%$ & $9.49 \%$ & $-30.5 \mathrm{~dB}$ & $-30.8 \mathrm{~dB}$ \\
\hline CS 6 & 1.38 p.u. & $0.15 \%$ & $15.41 \%$ & $-26 \mathrm{~dB}$ & $-26.3 \mathrm{~dB}$ & 1.87 p.u. & $0.08 \%$ & $10.31 \%$ & $-30.5 \mathrm{~dB}$ & $-30.8 \mathrm{~dB}$ \\
\hline CS 7 & 2.24 p.u. & $8.6 \%$ & $7.6 \%$ & $-51 \mathrm{~dB}$ & $-51.5 \mathrm{~dB}$ & 2.24 p.u. & $4.9 \%$ & $6.7 \%$ & $-50.8 \mathrm{~dB}$ & $-51.4 \mathrm{~dB}$ \\
\hline CS 8 & 2.24 p.u. & $6.8 \%$ & $7.6 \%$ & $-51 \mathrm{~dB}$ & $-51.6 \mathrm{~dB}$ & 2.24 p.u. & $0.32 \%$ & $6.15 \%$ & $-50.8 \mathrm{~dB}$ & $-51.4 \mathrm{~dB}$ \\
\hline
\end{tabular}

terminal indicates for which power flow variations a stable and acceptable operation can be achieved for that terminal for all droop gain value combinations. In the optimal case, each terminal should achieve an APTC $\geq 2$ p.u. for a wide range of droop gain combinations in order to be able to withstand disturbances and power flow variations up to its rated power in both power flow directions.

The APTC for the sum of both GSVSCs $\left(p_{\text {gridside }}\right)$, shown in Fig. 9b, indicates how much power can be transferred from the WFVSC to the GSVSCs (upper limit) and how much could be transferred from both GSVSCs to an uncontrolled dc node (lower limit). In this scenario the WFVSC should be imagined not as wind farm, but as a weak grid not participating in the dc voltage control.

When analyzing the APTC of the various CSs, it is of main interest to find the maximum APTC value of a single terminal, i.e. exemplary for CS 8 to determine the droop gain combination where the range between the upper and lower limit is the highest in Fig. 9a. Further, it is of main interest to find the maximum APTC value for the whole $p_{\text {gridside }}$ (Tab. I \& Tab. III), since in the case of just maximizing the APTC of a single terminal the APTC of the second terminal will be minimized at the same time, as shown in Fig. 9a (maximum at $k_{\text {droop }}=0.0001$ and $k_{\text {droop,gs } 2}=0.1$, but minimum at $k_{\text {droop }}=0.1$ and $\left.k_{\text {droop }, g s 2}=0.0001\right)$. Thus, the maximum
APTC for the whole $p_{\text {gridside }}$ is resembled by the maximum range between the upper and lower boundary in Fig. $9 b$.

Additionally, the eigenvalues with the lowest damping ratio at both limits have been analyzed in order to determine possible limitations and differences between the CSs (Tab. II, Tab. IV). Both analyses have been carried out once for each investigated tuning in order to be able to point out the consequences of a different tuning.

1) Analysis of the maximum APTC of a single terminal: The results of the analysis of the maximum APTC of a single terminal in the case both terminals use the same CS is given in Tab. I. The participation factor analysis of the lowest damped eigenvalues at both limits is given in Tab. II.

The results indicate that the four CSs, where the dc voltage is controlled in the second loop, outperform the remaining CSs. That means, CS 3, 4, 7 and 8 achieve a significant larger APTC. Additionally, they achieve significant lower maximum singular values in steady state, $\bar{\sigma}\left(E_{w}(0)\right)$. However, all CSs fulfill the requirements of the stability margin minimizing the voltage deviation $\left(\bar{\sigma}\left(E_{w}(0)\right) \geq-23.01 \mathrm{~dB}\right)$. The results indicate further that the results are almost the same for the slow tuning.

For all CSs the APTC of a single terminal is maximized in case the difference of the droop gains is high, which minimizes the APTC of the second terminal at the same time, as shown above

TABLE II

PARTICIPATION FACTOR ANALYSIS FOR MAXIMUM APTC OF A SINGLE GSVSC $\llbracket$ GSVSC1 + AC GRID 1, GSVSC2 + AC GRID 2, WFVSC + AC GRID, $\llbracket$ DC GRID

\begin{tabular}{|c|c|c|c|c|c|c|c|c|}
\hline \multicolumn{9}{|c|}{ Fast Response Time } \\
\hline Control & \multicolumn{8}{|c|}{ Highest participation factors of lowest damped EV } \\
\hline Structure & \multicolumn{4}{|c|}{ lower limit } & \multicolumn{4}{|c|}{ upper limit } \\
\hline CS 1 & $32 \% i_{g, d, g 1}$ & $30 \% v_{o, d, g 1}$ & $18 \% v_{o, q, g 1}$ & $17 \% i_{g, q, g 1}$ & $45 \% v_{o, q, g 1}$ & $43 \% i_{g, q, g 1}$ & $5 \% i_{l, q, g 1}$ & $3 \% \chi_{q, g 1}$ \\
\hline CS 2 & $50 \% i_{l, d, g 1}$ & $50 \% \quad v_{d c, g 1}$ & $\gamma$ & 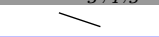 & $37 \% i_{g, d, w f}$ & $26 \% v_{o, d, w f}$ & $11 \% \chi_{d, w f}$ & $8 \% v_{o, q, w f}$ \\
\hline CS 3 & $25 \% i_{d c, w g 2}$ & $22 \% v_{d c, w}$ & $21 \% v_{d c, g 2}$ & $13 \% i_{d c, w g 1}$ & $31 \% v_{o, d, g 1}$ & $26 \% i_{g, d, g 1}$ & $17 \% v_{o, q, g 1}$ & $16 \% i_{g, q, g 1}$ \\
\hline CS 4 & $24 \% i_{d c, w g 2}$ & $23 \% v_{d c, w}$ & $21 \% v_{d c, g 2}$ & $13 \% i_{d c, w g 1}$ & $31 \% v_{o, d, g 1}$ & $26 \% i_{g, d, g 1}$ & $17 \% v_{o, q, g 1}$ & $16 \% i_{g, q, g 1}$ \\
\hline CS 5 & $39 \% i_{g, d, g 1}$ & $29 \% v_{o, d, g 1}$ & $10 \% v_{d c, g 1}$ & $8 \% v_{o, q, g 1}$ & $32 \% v_{o, d, g 2}$ & $26 \% i_{g, d, g 2}$ & $16 \% v_{o, q, g 2}$ & $15 \% i_{g, q, g 2}$ \\
\hline CS 6 & $39 \% i_{g, d, g 1}$ & $29 \% v_{o, d, g 1}$ & $8 \% v_{d c, g 1}$ & $8 \% v_{o, q, g 1}$ & $32 \% v_{o, d, g 2}$ & $25 \% i_{g, d, g 2}$ & $18 \% v_{o, q, g 2}$ & $16 \% i_{g, q, g 2}$ \\
\hline CS 7 & $30 \% v_{o, q, g 2}$ & $27 \% i_{g, q, g 2}$ & $19 \% v_{o, d, g 2}$ & $19 \% i_{g, d, g 2}$ & $31 \% v_{o, d, g 1}$ & $26 \% i_{g, d, g 1}$ & $18 \% v_{o, q, g 1}$ & $16 \% i_{g, q, g 1}$ \\
\hline CS 8 & $25 \% i_{d c, w g 2}$ & $23 \% v_{d c, w}$ & $21 \% v_{d c, g 2}$ & $13 \% i_{d c, w g 2}$ & $31 \% v_{o, d, g 1}$ & $26 \% i_{d, g, g 1}$ & $18 \% v_{o, q, g 1}$ & $16 \% i_{g, q, g 1}$ \\
\hline \multicolumn{9}{|c|}{ Slow Response Time } \\
\hline CS 3 & $23 \% v_{d c, w}$ & $23 \% i_{d c, w g 2}$ & $17 \% i_{d c, w g 1}$ & $16 \% v_{d c, g 2}$ & $24 \% v_{d c, g 1}$ & $24 \% i_{d c, g g}$ & $23 \% v_{d c, g 2}$ & $7 \% \chi_{d, g 1}$ \\
\hline CS 4 & $23 \% v_{d c, w}$ & $22 \% i_{d c, w g 2}$ & $17 \% i_{d c, w g 1}$ & $16 \% v_{d c, g 2}$ & $23 \% i_{d c, g g}$ & $23 \% v_{d c, g 1}$ & $23 \% v_{d c, g 2}$ & $7 \% \chi_{d, g 1}$ \\
\hline CS 5 & $39 \% v_{d c, w}$ & $20 \% i_{d c, w g 1}$ & $12 \% i_{d c, w g 2}$ & $9 \% v_{d c, g 2}$ & $38 \% v_{o, d, g 1}$ & $27 \% i_{g, d, g 1}$ & $10 \% v_{o, q, g 1}$ & $9 \% i_{g, q, g 1}$ \\
\hline CS 6 & $39 \% v_{d c, w}$ & $20 \% i_{d c, w g 1}$ & $12 \% i_{d c, w g 2}$ & $9 \% v_{d c, g 2}$ & $28 \% v_{o, d, g 2}$ & $24 \% i_{g, d, g 2}$ & $22 \% v_{o, q, g 2}$ & $20 \% i_{g, q, g 2}$ \\
\hline $\mathrm{CS} 7$ & $34 \% v_{d c, g 1}$ & $21 \% i_{d c, w g 1}$ & $11 \% v_{d c, w}$ & $11 \% \chi_{d, g 1}$ & $34 \% v_{d c, g 1}$ & $24 \% i_{d c, w g 1}$ & $12 \% v_{d c, w}$ & $11 \% \chi_{d, g 1}$ \\
\hline CS 8 & $23 \% i_{d c, w g 2}$ & $23 \% v_{d c, w}$ & $17 \% i_{d c, w g 1}$ & $16 \% v_{d c, g 2}$ & $25 \% v_{d c, g 1}$ & $24 \% i_{d c, g g}$ & $23 \% v_{d c, g 2}$ & $8 \% \chi_{d, g 1}$ \\
\hline
\end{tabular}


TABLE III

COMPARISON OF MAXIMUM APTC OF SUM OF GSVSCS FOR VARIOUS CONTROL STRUCTURES REQUIREMENTS: $₫$ FULFILLED, FULFILLED BUT CLOSE TO BOUNDARY, $₫$ NOT FULFILLED

\begin{tabular}{|c|c|c|c|c|c|c|c|c|c|c|}
\hline \multirow{4}{*}{$\begin{array}{l}\text { Control } \\
\text { Structure }\end{array}$} & \multicolumn{5}{|c|}{ Fast Response Time } & \multicolumn{5}{|c|}{ Slow Response Time } \\
\hline & \multirow{3}{*}{$\begin{array}{l}\text { Max Range } \\
p_{\text {gridside }}\end{array}$} & \multirow{2}{*}{\multicolumn{2}{|c|}{$\begin{array}{c}\text { Damping Ratio } \\
\text { of lowest damped EV }\end{array}$}} & \multicolumn{2}{|c|}{$\bar{\sigma}\left(E_{w}(0)\right)$} & \multirow{3}{*}{$\begin{array}{c}\text { Max Range } \\
p_{\text {gridside }}\end{array}$} & \multirow{2}{*}{\multicolumn{2}{|c|}{$\begin{array}{c}\text { Damping Ratio } \\
\text { of lowest damped EV }\end{array}$}} & \multicolumn{2}{|c|}{$\bar{\sigma}\left(E_{w}(0)\right)$} \\
\hline & & & & \multirow{2}{*}{$\begin{array}{l}\text { lower } \\
\text { limit }\end{array}$} & \multirow{2}{*}{$\begin{array}{l}\text { upper } \\
\text { limit }\end{array}$} & & & & \multirow{2}{*}{$\begin{array}{l}\text { lower } \\
\text { limit }\end{array}$} & \multirow{2}{*}{$\begin{array}{l}\text { upper } \\
\text { limit }\end{array}$} \\
\hline & & 1. limit & u. limit & & & & 1. limit & u. limit & & \\
\hline CS 1 & 1.97 p.u. & $0.23 \%$ & $13.92 \%$ & $-26 \mathrm{~dB}$ & $-27.3 \mathrm{~dB}$ & & & & & \\
\hline CS 2 & 1.95 p.u. & $0.16 \%$ & $0.19 \%$ & $-23.7 \mathrm{~dB}$ & $-24 \mathrm{~dB}$ & & & & & \\
\hline CS 3 & 3.02 p.u. & $6.19 \%$ & $8.22 \%$ & $-61.3 \mathrm{~dB}$ & $-62 \mathrm{~dB}$ & 2.9 p.u. & $0.002 \%$ & $5.8 \%$ & $-27.3 \mathrm{~dB}$ & $-29 \mathrm{~dB}$ \\
\hline CS 4 & 2.97 p.u. & $8.98 \%$ & $7.99 \%$ & $-36.6 \mathrm{~dB}$ & $-37.3 \mathrm{~dB}$ & 2.97 p.u. & $2.21 \%$ & $5.87 \%$ & $-28.9 \mathrm{~dB}$ & $-29.6 \mathrm{~dB}$ \\
\hline CS 5 & 2.48 p.u & $0.06 \%$ & $15.49 \%$ & $-26.4 \mathrm{~dB}$ & $-26.7 \mathrm{~dB}$ & 2.76 p.u. & $0.5 \%$ & $11.12 \%$ & $-26.4 \mathrm{~dB}$ & $-26.7 \mathrm{~dB}$ \\
\hline CS 7 & 2.47 p.u & $0.1 \%$ & $9.2 \%$ & $-32 \mathrm{~dB}$ & $-32.3 \mathrm{~dB}$ & 2.59 p.u. & $0.07 \%$ & $7.26 \%$ & $-28.8 \mathrm{~dB}$ & $-29.1 \mathrm{~dB}$ \\
\hline CS 8 & 3.02 p.u & $6.7 \%$ & $8.37 \%$ & $-53.5 \mathrm{~dB}$ & $-53.9 \mathrm{~dB}$ & 2.97 p.u. & $0.08 \%$ & $5.6 \%$ & $-27.8 \mathrm{~dB}$ & $-28.2 \mathrm{~dB}$ \\
\hline
\end{tabular}

in Fig. 9a. The reason for this is the current limit of $2265 \mathrm{~A}$ (= 0.755 p.u.), which limits the current for each line and therefore makes it necessary to minimize the power transfer of the second terminal, in order to transfer as much power as possible from the WSVSC through all three cables to one specific terminal. This might make the results rather specific for this topology, however, the analysis still points out which CSs are capable of withstanding large droop gain deviations within a MT-HVDC grid without leading to instability (in rectifier mode). This is indicated by the very low damping ratios of the lowest damped eigenvalues at the lower limit for CS 1 , 2, 5 and 6 , as shown in Tab. II. This means further that the APTC of those CSs decreases further for a stability margin demanding a minimum damping ratio of $3 \%$, which leads to an even bigger deviation between the highest and lowest APTC of the various CSs.

The participation factor analysis in Tab. II shows further, which states have a participation in the modes of those eigenvalues with the lowest damping ratio. In fact, in case of the fast tuning, the eigenvalues corresponding to the very low damping ratios at the lower limit (CS 1, 5\&6) are related to the GSVSC1, i.e. the GSVSC transferring as much power as possible from the ac to the dc side. Hence, the instability is caused by the terminal and the connected ac grid.

While in case of the slower tuning, the damping ratios at the lower limit do not differ so much anymore, i.e. the ones of the better performing CSs decrease while the damping ratios of the remaining ones remain low. Only CS 7 still fulfills the stability margin in this case. Further, with the slower tuning, the lower limit is related to oscillation within the dc grid for all CSs, as the participation factor analysis indicates (Tab. II). Thus, a faster tuning leads to better damped dc oscillations.

2) Analysis of the maximum APTC of the sum of both GSVSCs: The results of the maximum APTC of all GSVSCs are given in Tab. III. It is shown that the CSs 3 and 8 still outperform the others in case of the fast tuning. While CS 4 still achieves a comparable APTC, CS 3 and 8 achieve significant lower maximum singular values in steady state, $\bar{\sigma}\left(E_{w}(0)\right)$, i.e. smaller voltage deviation induced by a variation of the active power of the WFVSC.

The results indicate further that in order to maximize the APTC of all GSVSCs equal droop gains (or small deviations) are preferable, the only exception here is CS 7 .

The analysis additionally shows that with slower tuning the maximum singular values of CS 3, 4, 7 and 8 decrease, while the ones of CS 5 and 6 remain approximately constant. Further, with that tuning, the APTC of the CSs 5, 6 and 7 increase while the ones of 3 and 8 decrease, which brings the APTC of all CSs closer to each other. Hence, the various CSs tend to favor different tunings / the impact of the tuning on the CSs

TABLE IV

PARTICIPATION FACTOR ANALYSIS FOR MAXIMUM APTC OF THE SUM OF BOTH GSVSCS $\square$ GSVSC $1+$ AC GRID 1, GSVSC2 + AC GRID 2, WFVSC + AC GRID, $\llbracket$ DC GRID

\begin{tabular}{|c|c|c|c|c|c|c|c|c|}
\hline \multicolumn{9}{|c|}{ Fast Response Time } \\
\hline Control & \multicolumn{8}{|c|}{ Highest participation factors of lowest damped EV } \\
\hline Structure & \multicolumn{4}{|c|}{ lower limit } & \multicolumn{4}{|c|}{ upper limit } \\
\hline CS 1 & $37 \% i_{g, d, g 1}$ & $30 \% v_{o, d, g 1}$ & $11 \% v_{o, q, g 1}$ & $10 \% i_{g, q, g 1}$ & $45 \% v_{o, q, g 2}$ & $42 \% i_{g, q, g 1}$ & $5 \% i_{l, q, g 2}$ & $2 \% \chi_{q, g 2}$ \\
\hline CS 2 & $46 \% v_{d c, w}$ & $24 \% i_{d c, w g 1}$ & $24 \% i_{d c, w g 2}$ & $2 \% v_{d c, g 2}$ & $37 \% i_{g, d, w f}$ & $26 \% v_{o, d, w f}$ & $11 \% \chi_{d, w f}$ & $8 \% v_{o, q, w f}$ \\
\hline CS 3 & $26 \% v_{d c, w}$ & $15 \% \chi_{d, g 1}$ & $15 \% \chi_{d, g 2}$ & $11 \% v_{d c, g 1}$ & $15 \% v_{o, d, g 1}$ & $15 \% v_{o, d, g 2}$ & $13 \% i_{g, d, g 1}$ & $13 \% i_{g, q, g 2}$ \\
\hline CS 4 & $19 \% v_{d c, w}$ & $18 \% i_{d c, w g 1}$ & $17 \% v_{d c, g 1}$ & $16 \% i_{d c, w g 2}$ & $29 \% v_{o, d, g}$ & $25 \% i_{g, d, g 2}$ & $19 \% v_{o, q, g 2}$ & $17 \% i_{g, q, g 2}$ \\
\hline CS 5 & $19 \% i_{g, d, g 1}$ & $19 \% i_{g, d, g 2}$ & $15 \% v_{o, d, g 1}$ & $15 \% v_{o, d, g 2}$ & $18 \% v_{o, q, g 1}$ & $18 \% v_{o, q, g 2}$ & $17 \% i_{g, q, g 1}$ & $17 \% i_{g, q, g 2}$ \\
\hline CS 6 & $19 \% i_{g, d, g 1}$ & $19 \% i_{g, d, g 2}$ & $15 \% v_{o, d, g 2}$ & $15 \% v_{o, d, g 1}$ & $17 \% v_{o, q, g 1}$ & $17 \% v_{o, q, g 2}$ & $16 \% i_{g, q, g 1}$ & $16 \% i_{g, q, g 2}$ \\
\hline CS 7 & $34 \% i_{g, d, g 2}$ & $31 \% v_{o, d, g 2}$ & $16 \% v_{o, q, g 2}$ & $14 \% i_{g, q, g 2}$ & $32 \% v_{o, d, g 1}$ & $26 \% i_{g, d, g 1}$ & $17 \% v_{o, q, g 1}$ & $15 \% i_{g, q, g 1}$ \\
\hline CS 8 & $25 \% v_{d c, w}$ & $15 \% \chi_{d, g 1}$ & $15 \% \chi_{d, g 2}$ & $11 \% v_{d c, g 1}$ & $15 \% v_{o, d, g 1}$ & $15 \% v_{o, d, g 2}$ & $13 \% i_{g, d, g 1}$ & $13 \% i_{g, d, g 2}$ \\
\hline \multicolumn{9}{|c|}{ Slow Response Time } \\
\hline CS 3 & $23 \% v_{d c, w}$ & $19 \% i_{d c, w g 1}$ & $19 \% i_{d c, w g 2}$ & $13 \% v_{d c, g 1}$ & $24 \% i_{d c, g g}$ & $23 \% v_{d c, g 1}$ & $23 \% v_{d c, g 2}$ & $6 \% \chi_{d, g 1}$ \\
\hline CS 4 & $24 \% v_{d c, w}$ & $17 \% \chi_{d, g 1}$ & $20 \% \chi_{d, g 2}$ & $13 \% v_{d c, g 1}$ & $24 \% i_{d c, g g}$ & $24 \% v_{d c, g 1}$ & $24 \% v_{d c, g 2}$ & $7 \% \chi_{d, g 2}$ \\
\hline CS 5 & $38 \% v_{d c, w}$ & $16 \% i_{d c, w g 1}$ & $16 \% i_{d c, w g 2}$ & $8 \% \chi_{d, g 2}$ & $17 \% v_{o, d, g 1}$ & $17 \% v_{o, d, g 2}$ & $13 \% i_{g, d, g 1}$ & $13 \% i_{g, d, g 2}$ \\
\hline CS 6 & $38 \% v_{d c, w}$ & $16 \% i_{d c, w g 1}$ & $16 \% i_{d c, w g 2}$ & $7 \% \chi_{d, g 1}$ & $34 \% v_{o, d, g 1}$ & $26 \% i_{g, d, g 1}$ & $16 \% v_{o, q, g 1}$ & $14 \% i_{g, q, g 1}$ \\
\hline CS 7 & $37 \% i_{g, d, g 2}$ & $32 \% v_{o, d, g 2}$ & $12 \% v_{o, q, g 2}$ & $11 \% i_{g, q, g 2}$ & $34 \% v_{d c, g 1}$ & $25 \% i_{d c, w g 1}$ & $13 \% v_{d c, w}$ & $10 \% \chi_{d, g 1}$ \\
\hline CS 8 & $21 \% v_{d c, w}$ & $19 \% i_{d c, w g 1}$ & $19 \% i_{d c, w g 2}$ & $14 \% v_{d c, g 1}$ & $25 \% i_{d c, g g}$ & $24 \% v_{d c, g 1}$ & $24 \% v_{d c, g 2}$ & $6 \% \chi_{d, g 1}$ \\
\hline
\end{tabular}


varies for the different CSs.

The damping ratios of the lowest damped eigenvalues, given in Tab. IV, indicate significant difference between the CSs. In fact, a stability margin demanding a minimum damping ratio of $3 \%$ with a fast tuning will further decrease the APTC of all CSs except 3,4 and 8. This will lead to even higher APTC deviation between the various CSs. The lowest damped eigenvalues of the lower limit of all these three cases are related to the dc grid and the droop controller. Whereas in all other cases (except CS 2) the lowest damped eigenvalues of the lower limit are related to ac values of either GSVSC1 or GSVSC2. Given the low damping ratios of those eigenvalues, for CSs 1, 5,6 and 7 the lower limit is caused by the ac side oscillations of one of the GSVSCs.

The lowest damped eigenvalues of the upper limit on the other hand have for all CSs a comparable high damping ratio, except for CS 2, where the upper limit is apparently related to oscillations within the ac grid of the WFVSC.

3) Conclusion for both GSVSCs using the same CS: Two important aspects of the APTC have been analyzed, first the maximization of power transfer of a single terminal and then the maximization of APTC of the whole system. The CSs 3, 4 and 8 outperform the remaining CSs in both aspects. In both cases, they obtain wider APTC, higher damping ratios of the lowest damped eigenvalue, as well significant lower maximum singular values. Furthermore, the maximum APTC is only limited by the current limitations.

Additionally, the impact of two different tunings have been compared. The tuning hardly impacts the analysis of maximizing the APTC of a single terminal, while the influence on the second analysis is not negligible. It is obvious that a faster damping leads to better damped dc oscillations. This is indicated by the comparison of the eigenvalue movement for a variation of $k_{\text {droop }}$ in Fig. 10. It is obvious that both pairs of complex eigenvalues with $\operatorname{Im}\{\lambda\} \approx \pm 400$ are moved to regions with higher damping ratio in the left half-plane. A participation factor analysis indicates that these eigenvalues are related to dc states.

Further, it has been shown that all CSs are not limited by a set of maximum singular values. The damping ratio stability margin on the other hand is limiting specific CSs while others are fulfilling this stability margin without further limitation of the APTC. Hence, in case of demanding a minimum damping ratio of $3 \%$, the differences between the APTC of the various CSs will be even more significant.

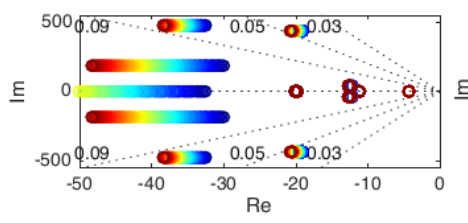

(a) Slow Tuning (b) Fast Tuning

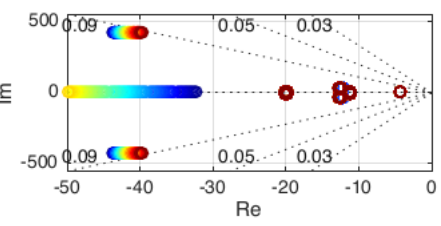

Fig. 10. Movement of the EV and the damping ratios for a variation of $k_{\text {droop }}=0$ p.u. (blue) to 0.1 p.u. (red) in case both GSVSCs use CS 3
TABLE V

MAXIMUM APTC - REQUIREMENTS: FULFILLED

\begin{tabular}{cccccc}
\hline Control & Max Range & \multicolumn{2}{c}{$\bar{\sigma}\left(E_{w}(0)\right)$} & \multicolumn{2}{c}{ Low. Damp. Ratio } \\
Structures & $p_{\text {gridside }}$ & 1. limit & u. limit & 1. limit & u. limit \\
\hline $4 \& 3$ & 3.02 p.u. & $-61.33 \mathrm{~dB}$ & $-61.99 \mathrm{~dB}$ & $6.2 \%$ & $8.2 \%$ \\
$8 \& 3$ & 3.02 p.u. & $-53.5 \mathrm{~dB}$ & $-53.95 \mathrm{~dB}$ & $6.7 \%$ & $8.4 \%$ \\
$8 \& 4$ & 3.02 p.u. & $-61.33 \mathrm{~dB}$ & $-61.99 \mathrm{~dB}$ & $6.2 \%$ & $8.2 \%$ \\
\hline
\end{tabular}

\section{B. Analysis of the Case where both GSVSCs use different CSs}

In order to determine the consequences of combining different CSs within one grid and finding the most beneficial combination, the most promising CSs from the previous analysis have been combined. Thus, GSVSC1 and GSVSC2 will use different droop control structures with the fast tuning in the following. In particular, the combinations of CS 3, 4 and 8 have been analyzed in detail, due to the most promising results in the previous section.

The analysis indicates that the results for a maximization of the APTC of the single terminal do not differ from the previous analysis for the specific CSs. Thus, the focus is put on the maximization of the APTC of the whole system, the results are given in Tab. V. All the three combinations fulfill all requirements and achieve the same APTC. However, both combinations including CS 4 achieve lower maximum singular values than the combination of CS 8 \& CS 3, which leads to lower voltage deviation at the GSVSCs induced by a power variation of the WFVSC. The maximum APTC of all these three combinations is limited by the current limit. Thus, with cables enabling a higher current limit the APTC will be further increased. However, this does not imply that for other current limitations different combinations of CSs might be more beneficial, since in the previous analysis it was already shown that these three CSs outperform the remaining once already with this current limit.

\section{CONCLUSION}

This paper presented a methodology to determine the active power transfer capability of single terminals within a MTDC grid. A case study was used to analyze deviations in the APTC, considering different stability margins due to the use of various dc voltage droop control structures and two different tunings. It was shown that fast tuning leads to better damping of dc oscillations. Further, it was shown that three different CSs outperform the remaining five. These three have been combined with each other in order to determine the most beneficial combination. In fact, a combination of a control structure using the dc voltage and the ac current (CS 4) with either a control structure using dc voltage and active power measured on the ac side (CS 8) or using dc voltage and dc current (CS 3) leads to even lower voltage deviation induced by power variations of the wind farm. However, additional studies are needed to verify the results for other topologies.

\section{REFERENCES}

[1] P. Kundur, N. J. Balu, and M. G. Lauby, Power system stability and control. McGraw-Hill Professional, 1994. 
[2] A. Y. Nilanjan Ray Chaudhuri, Balarko Chaudhuri, Rajat Majumder, Multi-Terminal Direct-Current Grids: Modeling, Analysis, and Control. Hoboken, New Jersey (USA): John Wiley \& Sons, Inc., 2014.

[3] A. Orths, A. Hiorns, R. van Houtert, L. Fisher, and C. Fourment, "The European North Seas Countries' Offshore Grid initiative - The way forward," 2012 IEEE Power \& Energy Society General Meeting. New Energy Horizons - Opportunities and Challenges, pp. 1-8, 2012.

[4] G. Bathurst and P. Bordignan, "Delivery of the Nan'ao Multi-terminal VSC-HVDC System," in Cigré International Symposium - Across Borders - HVDC Systems and Market Integration, no. December 2013, Lund, 2015, pp. 1-12.

[5] L. I. Xuan, M. A. Yulong, Y. U. E. Bo, M. A. Weimin, and C. Dong, "Study on Discharge Characteristics of DC System in Zhoushan MultiTerminal VSC-HVDC Transmission Project," in Cigré International Symposium - Across Borders - HVDC Systems and Market Integration, Lund, 2015.

[6] C. D. Barker and R. Whitehouse, "Autonomous converter control in a multi-terminal HVDC system," in 9th IET International Conference on $A C$ and DC Power Transmission, 2010. London: IET, 2010, pp. 1-5.

[7] T. M. Haileselassie and K. Uhlen, "Power System Security in a Meshed North Sea HVDC Grid," Proceedings of the IEEE, vol. 101, no. 4, pp. 978-990, 2013.

[8] V. Akhmatov, M. Callavik, C. M. Franck, S. E. Rye, T. Ahndorf, M. K. Bucher, H. Muller, F. Schettler, and R. Wiget, "Technical guidelines and prestandardization work for first HVDC Grids," IEEE Transactions on Power Delivery, vol. 29, no. 1, 2014.

[9] R. T. Pinto, S. F. Rodrigues, and P. Bauer, "Comparison of direct voltage control methods of multi-terminal DC (MTDC) networks through modular dynamic models," in Proceedings of the 2011-14th European Conference on Power Electronics and Applications (EPE 2011), Birmingham, 2011.

[10] J. Liang, T. Jing, O. Gomis-Bellmunt, J. Ekanayake, and N. Jenkins, "Operation and Control of Multiterminal HVDC Transmission for Offshore Wind Farms," IEEE Transactions on Power Delivery, vol. 26, no. 4, pp. 2596-2604, 2011.

[11] P. Rault, F. Colas, X. Guillaud, and S. Nguefeu, "Method for small signal stability analysis of VSC-MTDC grids," 2012 IEEE Power and Energy Society General Meeting, 2012.

[12] W. Wang, M. Barnes, and O. Marjanovic, "Droop control modelling and analysis of multi-terminal VSC-HVDC for offshore wind farms," in 10th IET International Conference on AC and DC Power Transmission, 2012, pp. 1-6.

[13] T. M. Haileselassie and M. Molinas, "Multi-terminal VSC-HVDC system for integration of offshore wind farms and green electrification of platforms in the North Sea," in Nordic Workshop on Power and Industrial Electronics (NORPIE/2008), 2008

[14] O. Gomis-Bellmunt, J. Liang, J. Ekanayake, and N. Jenkins, "Voltagecurrent characteristics of multiterminal HVDC-VSC for offshore wind farms," Electric Power Systems Research, vol. 81, no. 2, pp. 440-450, 2011.

[15] L. Xu, L. Yao, and M. Bazargan, "DC grid management of a multiterminal HVDC transmission system for large offshore wind farms," in International Conference on Sustainable Power Generation and Supply, 2009. IEEE, 2009, pp. 1-7.

[16] R. T. Pinto, S. Rodrigues, P. Bauer, and J. Pierik, "Operation and control of a multi-terminal DC network," IEEE ECCE Asia Downunder 2013, pp. 474-480, 2013.

[17] F. D. Bianchi and O. Gomis-Bellmunt, "Droop control design for multiterminal VSC-HVDC grids based on LMI optimization," in 50th IEEE Conference on Decision and Control and European Control Conference, 2011, pp. 4823-4828.

[18] L. Xu and L. Yao, "DC voltage control and power dispatch of a multi-terminal HVDC system for integrating large offshore wind farms," Renewable Power Generation, IET, vol. 5, no. 3, pp. 223-233, 2011.

[19] F. Thams, J. A. Suul, S. D'Arco, M. Molinas, and F. W. Fuchs, "Stability of DC Voltage Droop Controllers in VSC HVDC Systems," in PowerTech, Eindhoven 2015, Eindhoven, 2015.

[20] S. D'Arco, J. A. Suul, and M. Molinas, "Implementation and Analysis of a Control Scheme for Damping of Oscillations in VSC-based HVDC Grids," in 16th International Power Electronics and Motion Control Conference and Exposition, Antalya, Turkey 21-24, 2014, pp. 586-593.

[21] V. Blasko and V. Kaura, "A new mathematical model and control of a three-phase AC-DC voltage source converter," IEEE Transactions on Power Electronics, vol. 12, no. 1, pp. 116-123, 1997.

[22] V. Kaura and V. Blasko, "Operation of a phase locked loop system under distorted utility conditions," IEEE Transactions on Industry Applications, vol. 33, no. 1, pp. 58-63, 1997.
[23] C. Gavriluta, I. Candela, A. Luna, A. Gomez-Exposito, and P. Rodriguez, "Hierarchical Control of HV-MTDC Systems With Droop-Based Primary and OPF-Based Secondary," IEEE Transactions on Smart Grid, vol. 6, no. 3, pp. 1502-1510, 2015.

[24] H. Kolstad, Control of an Adjustable speed Hydro utilizing field programmable devices. Trondheim: Ph.D Dissertation, 2002.

[25] M. Malinowski, M. P. Kazmierkowski, and S. Bernet, "New simple active damping of resonance in three-phase PWM converter with LCL filter," in IEEE International Conference on Industrial Technology 2005 IEEE, 2005, pp. 861-865.

[26] O. Mo, M. Hernes, and K. Ljøkelsøy, "Active damping of oscillations in LC-filter for line connected, current controlled, PWM voltage source converters," in 10th European Conference on Power Electronics and Applications 2003, 2003.

[27] C. Bajracharya, M. Molinas, and J. A. Suul, "Understanding of tuning techniques of converter controllers for VSC-HVDC," in Proceedings of the Nordic Workshop on Power and Industrial Electronics, 2008.

[28] E. Prieto-Araujo, F. D. Bianchi, A. Junyent-Ferre, and O. GomisBellmunt, "Methodology for Droop Control Dynamic Analysis of Multiterminal VSC-HVDC Grids for Offshore Wind Farms," IEEE Transactions on Power Delivery, vol. 26, no. 4, pp. 2476-2485, 2011.

[29] R. L. Hendriks, G. C. Paap, and W. L. Kling, "Control of a multiterminal VSC transmission scheme for connecting offshore wind farms," European Wind Energy Conference, 2007.

[30] Y. Chen, G. Damm, and A. Benchaib, "Multi-Time-Scale Stability Analysis and Design Conditions of a VSC Terminal with DC Voltage Droop Control for HVDC Networks," in 53rd IEEE Conference on Decision and Control, Los Angeles, CA, 2014.

[31] B. K. Johnson, R. H. Lasseter, F. L. Alvarado, and R. Adapa, "Expandable multiterminal dc systems based on voltage droop," IEEE Transactions on Power Delivery, vol. 8, no. 4, 1993.

[32] S. Zhou, J. Liang, J. B. Ekanayake, and N. Jenkins, "Control of multiterminal VSC-HVDC transmission system for offshore wind power generation," in Proceedings of the 44th International Universities Power Engineering Conference, 2009, 2009.

[33] J. Dragon, L. Werner, and J. Hanson, "Effects of DC Voltage Droop Characteristics on Contingency Behaviour of AC / DC Systems," in 49th International Universities' Power Engineering Conference (UPEC), Cluj-Napoca, 2014.

[34] T. M. Haileselassie and K. Uhlen, "Impact of DC Line Voltage Drops on Power Flow of MTDC Using Droop Control," IEEE Transactions on Power Systems, vol. 27, no. 3, pp. 1441-1449, 2012.

[35] - "Precise control of power flow in multiterminal VSC-HVDCs using DC voltage droop control," 2012 IEEE Power and Energy Society General Meeting, pp. 1-9, 2012.

[36] — "Primary frequency control of remote grids connected by multiterminal HVDC," Power and Energy Society General Meeting, 2010 IEEE, pp. 1-6, 2010.

[37] G. Stamatiou and M. Bongiorno, "Decentralized converter controller for multiterminal HVDC grids," in 15th European Conference on Power Electronics and Applications (EPE), 2013. IEEE, 2013, pp. 1-10.

[38] T. K. Vrana, Y. Yang, D. Jovcic, S. Dennetière, J. Jardini, and H. Saad, "The CIGRE B4 DC Grid Test System," Cigre, Tech. Rep., 2013.

[39] G. Pinares, L. B. Tjernberg, L. A. Tuan, C. Breitholtz, and A.-A. Edris, "On the analysis of the dc dynamics of multi-terminal VSC-HVDC systems using small signal modeling," 2013 IEEE Grenoble Conference, pp. 1-6, 2013.

[40] E. Prieto-Araujo, A. Egea-Alvarez, S. F. Fekriasl, and O. GomisBellmunt, "DC voltage droop control design for multi-terminal HVDC systems considering AC and DC grid dynamics," IEEE Transactions on Power Delivery, vol. 31, no. 2, pp. 575 - 585, 2015.

[41] Maxima CAS Development Team, "Maxima, a Computer Algebra System," p. GNU General Public License (GPL), 2015. 


\section{APPENDIX}

TABLE VI

BASE VALUES OF PER UNIT SYSTEM AND PARAMETERS

\begin{tabular}{lc}
\hline Parameter & Value \\
\hline Rated voltage, $V_{S, L L, R M S}$ & $220 \mathrm{kV}$ \\
Rated power, $S_{b, g s v s c}$ & $1200 \mathrm{MVA}$ \\
Rated power, $S_{b, w f v s c}$ & $2 \cdot 1200 \mathrm{MVA}$ \\
Rated dc voltage, $V_{d c}$ & $400 \mathrm{kV}$ \\
Rated angular frequency, $\omega_{b}$ & $2 \pi 50 \mathrm{~s}-1$ \\
Base value for voltage defined as peak & $\sqrt{\frac{2}{3}} V_{S, L L, R M S}$ \\
value of phase voltage, $V_{b}$ & $S_{b}$ \\
Base value for currents defined as peak & $\sqrt{3} V_{S, L L, R M S}$ \\
value or rated RMS, $I_{b}$ & $\frac{V_{b}}{I_{b}}$ \\
Base value for impedance, $Z_{b}$ & $\frac{Z_{b}}{\omega_{b}}$ \\
Base value for filter inductance, $L_{b}$ & 1 \\
Base value for filter capacitance, $C_{b}$ & $\frac{1}{\omega_{b} Z_{b}}$ \\
Line resistance, $R$ & $2.611 \Omega \mathrm{mH} / \mathrm{km}$ \\
Line inductance, $L$ & $0.1908 \mu \mathrm{F} / \mathrm{km}$ \\
Line capacitance, $C$ & $67 \mathrm{~km}$ \\
Cable distances & $4.2 \mathrm{p} . \mathrm{u}$. \\
Equivalent dc capacitor, $c_{d c}$ & $1 \mathrm{p} . \mathrm{u}$. \\
Grid voltage, $\hat{v}_{g}$ & $0.08 \mathrm{p} . \mathrm{u}$. \\
Filter inductance, $l_{f}$ & $0.003 \mathrm{p} . \mathrm{u} .$. \\
Filter resistance, $r_{f}$ & $0.074 \mathrm{p} . \mathrm{u}$. \\
Filter capacitance, $c_{f}$ & $0.2 \mathrm{p} . \mathrm{u}$. \\
Grid inductance, $l_{g}$ & $0.01 \mathrm{p} . \mathrm{u}$. \\
Grid resistance, $r_{g}$ & $0 \mathrm{p} . \mathrm{u}$. \\
Reactive power reference, $q^{*}$ & $1 \mathrm{p} . \mathrm{u}$. \\
Ac voltage reference, $v_{o, d, w f}^{*}$ & $20 \mathrm{p} . \mathrm{u}$. \\
Low-Pass filter frequency, $\omega_{A D}$ & $0.2 \mathrm{p} . \mathrm{u}$. \\
Active damping parameter $(\mathrm{GSVSCs})$, & \\
$k_{a d, g s v c}$ & $1 \mathrm{p} . \mathrm{u}$. \\
Active damping parameter $(\mathrm{WFVSC})$, & \\
$k_{a d, w f v s c}$ &
\end{tabular}

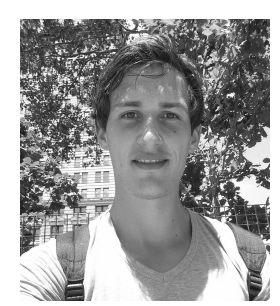

Florian Thams received the B.Sc. and M.Sc. in Business Administration and Engineering from the Christan Albrechts University of Kiel, Germany, in 2012 and 2015, respectively. From February 15 to June 15 he joined the Center of Electric Power and Energy at the Technical University of Denmark (DTU) as Research Assistant. Currently he is pursuing his $\mathrm{PhD}$ at the same institute working within the EU BestPath project.

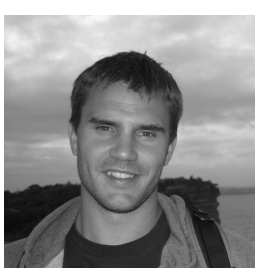

Robert Eriksson Robert Eriksson (M06) received his M.Sc. and Ph.D. degrees in electrical engineering from the KTH Royal Institute of Technology, Stockholm, Sweden, in 2005 and 2011, respectively. He held a position as Associate Professor with the Center for Electric Power and Energy (CEE), DTU Technical University of Denmark between 2013 and 2015. He is currently employed by the Swedish National Grid, focusing on research and development, at the Department of Market and System development. His research interests include power system dynamics and stability, HVDC systems, dc grids, and automatic control.

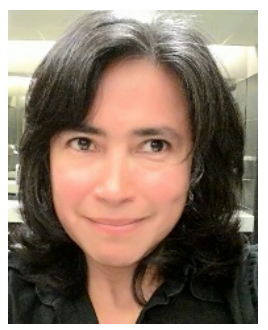

Marta Molinas Marta Molinas (M'94) received the Diploma degree in electromechanical engineering from the National University of Asuncion, Asuncion, Paraguay, in 1992; the Master of Engineering degree from Ryukyu University, Japan, in 1997; and the Doctor of Engineering degree from the Tokyo Institute of Technology, Tokyo, Japan, in 2000. She was a Guest Researcher with the University of Padova, Padova, Italy, during 1998. From 2004 to 2007, she was a Postdoctoral Researcher with the Norwegian University of Science and Technology (NTNU) and from 2008-2014 she has been professor at the Department of Electric Power Engineering at the same university. She is currently Professor at the Department of Engineering Cybernetics, NTNU. Her research interests include stability of power electronics systems, harmonics, instantaneous frequency, and non-stationary signals from the human and the machine. She is Associate Editor for the IEEE Journal JESTPE, IEEE PELS Transactions and Editor of the IEEE Transactions on Energy Conversion. Dr. Molinas has been an AdCom Member of the IEEE Power Electronics Society from 2009 to 2011. 